\section{Nuevas recomendaciones para el tratamiento de personas con infección por $\mathrm{VIH}^{1}$}

Palabras clave: síndrome de inmunodeficiencia adquirida, virus de la inmunodeficiencia humana, terapia ARMA, antirretrovíricos.

Elaborado a partir de U.S. Department of Health and Human Services, Guidelines for the use of antiretroviral agents in HIV-1-infected adults and adolescents, consultado en http://AIDSinfo. nih.gov el 22 de julio de 2003.
En julio de 2003, el Departamento de Salud y Servicios Sociales de los Estados Unidos de América (USDHHS) emitió sus recomendaciones más recientes en torno al tratamiento de adultos y adolescentes con infección por el virus de la inmunodeficiencia humana (VIH-1). Es la octava vez que estas recomendaciones, que se publicaron inicialmente en 1998, son revisadas por un panel de expertos del USDHHS que se reúne con regularidad con el fin exclusivo de incorporar cambios a medida que se hacen necesarios. Hasta hace relativamente poco, configurar un régimen terapéutico a partir de un contado número de antirretrovíricos era relativamente fácil. En años recientes, sin embargo, la proliferación de nuevos fármacos contra la infección por VIH ha llevado a la necesidad de modificar las recomendaciones con el fin de poder presentarle al profesional de la salud la creciente variedad de opciones terapéuticas de un modo estructurado y resumido que le permita elegir con facilidad el mejor tratamiento en un caso determinado.

Las nuevas recomendaciones del USDHHS difieren de las emitidas con anterioridad en varios aspectos importantes. En primer lugar, las grandes categorías de regímenes terapéuticos antirretrovíricos - los integrados por inhibidores nucleosídicos y no nucleosídicos de la transcriptasa inversa (INTI e INNTI, respectivamente) y los que se basan en inhibidores de las proteinasas (IP)han sido divididas en regímenes preferidos y en los que pueden considerarse como segunda opción, lo cual constituye una valiosa orientación para quien debe elegir entre un régimen y otro. Las nuevas recomendaciones son, además, más explícitas en lo que respecta a las medidas que deben tomarse en casos de fracaso terapéutico. Pero quizá su mayor importancia radica en que por primera vez se explican las ventajas y desventajas de los componentes de cada régimen antirretrovírico y los factores que deben tenerse presentes antes de administrarlo, lo cual le permite al profesional de la salud adaptar el tratamiento a las necesidades y características individuales de cada paciente.

En el momento en que se publicaron las nuevas recomendaciones del USDHHS se contaba con 22 formulaciones antirretrovíricas diferentes y 19 fármacos anti-VIH aprobados por la Administración de Alimentos y Medicamentos (FDA) de los Estados Unidos. Cabe esperar que sigan surgiendo nuevos tipos de agentes 
terapéuticos contra el VIH-1, por lo que el panel de expertos revisores del USDHHS se enfrenta a una labor que habrá de prolongarse indefinidamente. En las páginas que siguen se presentan de forma resumida los aspectos sobresalientes de las nuevas recomendaciones del USDHHS para el tratamiento de adultos y adolescentes infectados por el VIH-1, las cuales han de tomarse como complemento de las normas terapéuticas emitidas por los Institutos Nacionales de Salud de los Estados Unidos de América (1), que fueron publicadas por los Centros para el Control y la Prevención de Enfermedades (Atlanta, Georgia, Estados Unidos) en 1996. El documento del USDHHS donde aparecen las recomendaciones para el tratamiento de adultos y adolescentes infectados por el VIH-1 contiene también secciones sobre el tratamiento perinatal y pediátrico y la transmisión vertical del VIH-1; las medidas profilácticas recomendadas tras la exposición al VIH; el manejo de las complicaciones de la infección, entre ellas la tuberculosis; y el asesoramiento y la remisión de personas infectadas. No obstante, estos aspectos no se abordan en este resumen, como tampoco las medidas recomendadas frente al fracaso terapeútico.

Cabe hacer una última advertencia. No es la intención que las recomendaciones del USDHHS sustituyan el buen criterio clínico de médicos y otros profesionales de la salud con abundante experiencia en el manejo de personas infectadas por VIH, a quienes siempre deben acudir los profesionales que no se especializan en este tipo de atención.

\section{EL TRATAMIENTO DE ADOLESCENTES 2 Y ADULTOS CON INFECCIÓN POR VIH-1}

\section{Parámetros clínicos que deben orientar el tratamiento}

Toda decisión en torno a cuándo iniciar o cambiar el tratamiento antirretrovírico en pacientes asintomáticos infectados por VIH debe basarse en parámetros virológicos e inmunológicos esespecíficos: la cantidad de ácido ribonucleico (ARN) de VIH en el plasma (carga vírica) y el recuento plasmático de linfocitos $\mathrm{T}$ tipo $\mathrm{CD}^{+}$. Estos parámetros dan un indicio de la probabilidad de que la infección siga avanzando hasta convertirse en el síndrome de inmunodeficiencia adquirida (sida).

\footnotetext{
2 Se considera adolescente a una persona en la fase tardía de la pubertad o en la etapa $V$ de la tabla de crecimiento de Tanner (es decir, que ha alcanzado la madurez sexual).
}

Son tres las pruebas aprobadas hasta ahora por la FDA para determinar el pronóstico del paciente y monitorear su respuesta al tratamiento:

1. la reacción en cadena de la polimerasa (RCP) a base de la transcriptasa inversa del VIH-1 (Amplicor VIH-1 Monitor Test ${ }^{\circledR}$, versión 1.5, Roche Diagnostic)

2. la prueba de amplificación nucleica in vitro para la detección de ARN de VIH (NucliSens ${ }^{\circledR}$ HIV 1 QT, Organon Teknika), y

3. el ensayo in vitro de amplificación de señales a base de sonda de ácidos nucleicos [VERSANT ${ }^{\circledR}$ HIV-1 RNA 3.0 Assay (bDNA)].

En el caso de las dos primeras pruebas, el umbral de detección establecido es de 50 copias de ARN por mL de plasma; en el de la tercera, de 75 copias de ARN por $\mathrm{mL}$ de plasma. Dada la variabilidad que pueden tener los resultados obtenidos con las distintas pruebas, se aconseja que siempre se use un mismo tipo de ensayo para el seguimiento clínico de un paciente.

La carga vírica debe determinarse en el momento en que se diagnostica la infección por VIH y cada 3 a 6 meses en lo sucesivo, dependiendo de las circunstancias particulares del paciente. Las concentraciones plasmáticas del ARN del VIH también deben medirse cuando se comienza el tratamiento con antirretrovíricos y de 2 a 8 semanas después. La segunda medición tiene por objeto evaluar la respuesta inicial al tratamiento, que debe ser una disminución de la carga vírica de alrededor de $1.0 \log _{10}$ al cabo de pocas semanas. Dicha disminución debe sostenerse durante las semanas subsiguientes hasta que no haya carga vírica detectable y se ve afectada por el recuento basal de linfocitos $\mathrm{T} \mathrm{CD} 4^{+}$, la carga vírica inicial, la potencia del régimen terapéutico, la adhesión al tratamiento, la exposición previa a agentes antirretrovíricos y la presencia de infecciones oportunistas. La primera medición de la carga vírica y del recuento linfocitario debe ser doble para garantizar la precisión y uniformidad de los resultados.

Cuando no se observa una respuesta virológica de la magnitud aquí descrita es necesario evaluar la adhesión al tratamiento y descartar la mala absorción del fármaco o su interacción con otros medicamentos. El médico debe proceder a repetir las pruebas de ARN para documentar la falta de respuesta terapéutica o contemplar la posibilidad de un cambio de régimen. Una vez que se ha iniciado el tratamiento con antirretrovíricos, es preciso repetir las pruebas de detección de ARN vírico cada 3 a 4 meses con miras a evaluar la eficacia del tratamiento. Cuando se administra un 
tratamiento óptimo, la carga vírica a las 24 semanas de su inicio debe descender por debajo del umbral de detección ( $<50$ copias de $\mathrm{ARN} / \mathrm{mL}$ ), fenómeno que se correlaciona con una supresión vírica más prolongada que cuando la reducción es a 50-500 copias/mL. Si sigue habiendo concentraciones plsmáticas detectables de ARN de VIH al cabo de 16-24 semanas de tratamiento, es necesario repetir la prueba detectora a fin de confirmar el resultado y un cambio de régimen se debe contemplar.

En pacientes con enfermedad avanzada, el tratamiento con antirretrovíricos debe iniciarse tan pronto se obtiene la primera medición de la carga vírica, evitándose así una demora que podría ser perjudicial. No obstante, la realización de dos mediciones iniciales de la carga vírica, aun cuando supone un gasto considerable, le proporciona al médico la mejor información de base para el seguimiento ulterior del paciente. Las conconcentraciones plasmáticas de ARN de VIH deben medirse cuando hay otra infección y en las 4 semanas después de que esta ha sido erradicada mediante un tratamiento, como también cuando los síntomas de enfermedad desaparecen o se administra una vacuna.

Se considera mínimo un aumento o descenso de la carga vírica de $0,5-\log _{10}$, o bien un aumento del triple o una reducción a un tercio. En lo que respecta al recuento de linfocitos $\mathrm{T} \mathrm{CD}_{4}^{+}$, se considera grande un descenso del número absoluto de células $>30 \%$, o un descenso porcentual $>3 \%$, ambos en relación con el valor basal. En ocasiones hay discrepancia entre la concentración de ARN vírico y el recuento de linfocitos $\mathrm{T} \mathrm{CD}^{+}$, situación que puede desconcertar al clínico. En un caso tal, la primera suele ser más fiable que el segundo como base para la toma de decisiones terapéuticas, aunque hay excepciones. Se impone la necesidad de consultar a un especialista.

\section{Las pruebas de resistencia a los medicamentos antirretrovíricos}

Las pruebas para determinar si hay resistencia a los antirretrovíricos son importantes para orientar el tratamiento. Estas pruebas son de dos tipos: las de genotipificación, encaminadas a detectar mutaciones en los genes víricos relacionados con su susceptibilidad a los medicamentos, y las de fenotipificación, que miden la capacidad de un virus de reproducirse en ambientes con distintas concentraciones de antirretrovíricos. Los ensayos de genotipificación se pueden realizar con rapidez y los resultados pueden obtenerse 1 ó 2 semanas después de la obtención de la muestra. Su interpretación exige que el médico esté familiarizado con las diferentes mutaciones a las que puede conducir el uso de ciertos antirretrovíricos y que sea consciente de la posibilidad de que una mutación lleve a una reacción cruzada con otros medicamentos. En el caso de los ensayos de fenotipificación, la interpretación de los resultados se ve dificultada por la escasez de datos acerca del grado específico de resistencia que se asocia con el fracaso terapéutico. Una vez más, la consulta a un especialista se torna esencial.

Ambas clases de pruebas de resistencia poseen algunas desventajas adicionales, siendo las principales su carestía, la falta de un control de calidad uniforme para todos los tipos de ensayos y su poca sensibilidad para detectar especies víricas menores. Se recomienda que estas pruebas se efectúen solamente mientras el paciente está recibiendo el tratamiento antirretrovírico, y cualquier indicio de que no hay resistencia debe interpretarse con cautela y a la luz de los antecedentes terapéuticos del paciente. Estos ensayos son útiles en casos de fracaso virológico cuando el paciente está en tratamiento. No hay datos derivados de estudios prospectivos, sin embargo, que proporcionen bases para preferir uno $\mathrm{u}$ otro tipo de ensayo en distintas situaciones clínicas. Sin embargo, en pacientes con antecedentes terapéuticos complejos se aconseja realizar ambos tipos de pruebas a fin de obtener información complementaria.

La realización de pruebas de resistencia antes de iniciar el tratamiento con antirretrovíricos en pacientes con infección crónica por VIH no está tan claramente indicada. Las pruebas existentes podrían no detectar especies víricas que fueron transmitidas en el momento de la infección primaria, pero que, con el pasar del tiempo, se convirtieron en especies menores al no haber una presión farmacológica selectiva. No obstante, las pruebas podrían efectuarse cuando se considera que hay una fuerte probabilidad de que el paciente esté infectado por un VIH resistente, como sería el caso de una persona infectada por otra que estuviese recibiendo antirretrovíricos.

\section{El tratamiento de pacientes con infección sintomática y asintomática por VIH-1}

Los pacientes en quienes se ha confirmado la infección por VIH se dividen arbitrariamente en dos categorías: 1) los que tienen infección asintomática, y 2) los que tienen enfermedad sintomática (emaciación, moniliasis oral, fiebre de 
origen desconocido de más de 2 semanas de duración, etc.), incluido el sida, según la clasificación emitida por los CDC en 1993 (2). Todo paciente que pertenezca a la segunda categoría debe ser tratado con antirretrovíricos. En el caso de pacientes asintomáticos, la iniciación del tratamiento entraña mayor dificultad, como se verá más adelante. Independientemente de la presencia o ausencia de síntomas, sin embargo, todo paciente debe ser sometido a los siguientes:

Examen físico completo

Hemograma completo con química sanguínea, incluidas las transaminasas hepáticas y los lípidos del plasma

Recuento de linfocitos $\mathrm{T} \mathrm{CD}^{+}$

Determinación de ARN de VIH en el plasma

También deben realizarse las pruebas estándar para detectar infecciones oportunistas, aunque no haya indicios clínicos de su presencia. Estas pruebas son la de tuberculina; la prueba rápida de reaginina plasmática o VDRL; las pruebas serológicas de inmunoglobulina $G$ para toxoplasmosis; las pruebas serológicas para las hepatitis B y C; y un examen ginecológico con frotis de Papanicolaou. También se recomienda realizar otras pruebas si hay alguna indicación clínica de su necesidad. En algunos casos se aconseja realizar la prueba detectora de citomegalovirus.

Parámetros clínicos para el tratamiento de personas con infección asintomática. Los resultados de algunos ensayos clínicos apuntan a que el tratamiento con antirretrovíricos debe iniciarse en personas con infección asintomática por VIH que tengan un recuento de linfocitos $\mathrm{CD}^{+}<200$ células $/ \mathrm{mm}^{3}$. No se ha determinado, sin embargo, cuál es el momento más propicio para iniciar el tratamiento en personas sin síntomas cuyos recuentos linfocitarios son mayores. Hay quienes opinan que basta con que el recuento de estos linfocitos sea $<350$ células $/ \mathrm{mm}^{3}$ o con que la carga vírica sea $>55000$ copias de ARN vírico $/ \mathrm{mL}$. En cualquier caso, a la hora de tomar la decisión se deben sopesar también la disposición del paciente a ser tratado y las posibilidades de una buena adhesión al régimen terapéutico; el pronóstico de supervivencia sin enfermedad (basada en los valores basales de recuento linfocitario y carga vírica en el plasma) y la relación entre los riesgos y beneficios del tratamiento.

El tratamiento de personas asintomáticas puede reportar beneficios importantes:
1. Una supresión temprana de la reproducción del virus

2. La conservación de la función inmunitaria

3. La prolongación de la supervivencia sin enfermedad

4. Un menor riesgo de resistencia medicamentosa con supresión completa del virus

5. Una posible reducción del riesgo de transmisión del virus

Entre las desventajas del tratamiento precoz en personas asintomáticas se encuentran las siguientes:

1. La aparición de reacciones adversas

2. La incomodidad del tratamiento, con una consiguiente falta de adhesión

3. La aparición de resistencia al no suprimirse por completo el virus

4. La reducción del número de opciones terapéuticas para el futuro al producirse un ciclaje prematuro de los medicamentos

5. El riesgo de transmisión de virus resistentes a los medicamentos

6. Graves efectos tóxicos en el caso de algunos antirretrovíricos

7. La duración desconocida del efecto de los fármacos usados actualmente

No se ha detectado ninguna diferencia entre personas de uno $\mathrm{u}$ otro sexo en cuanto a la tendencia de la enfermedad a progresar, aunque se ha observado una posible diferencia en la carga vírica en función del sexo durante cierta fase de la infección. Un especialista puede, por precaución, regirse por un umbral de carga vírica más bajo en mujeres con recuentos de linfocitos $\mathrm{T} \mathrm{CD}^{+}>350$ células $/ \mathrm{mm}^{3}$, aunque ese umbral no se ha determinado y de momento no hay bases suficientes para adoptar medidas terapéuticas distintas en hombres y mujeres sin síntomas.

La adhesión al tratamiento. La falta de adhesión al tratamiento con antirretrovíricos, que es complejo y muy incómodo, es bastante común. Para mejorarla, los profesionales de la salud deben poner en práctica estrategias especiales: una intensa labor educativa encaminada a que el paciente entienda la importancia crítica de observar el tratamiento y el establecimiento, con la anuencia del paciente, de un plan terapéutico a largo plazo con metas bien definidas. Se impone la necesidad de seguir muy de cerca la evolución clínica del paciente y de proporcionarle a este asesoramiento continuo con miras a evitar la transmisión del VIH. Huelga decir que 
de la completa adhesión al tratamiento dependerán la supresión de la carga vírica y la reducción de la morbilidad y mortalidad. La adhesión parcial puede redundar, por añadidura, en resistencia al tratamiento.

El panel del USDHHS recomienda que algunas personas infectadas por el VIH, aun cuando estén asintomáticas, reciban terapia antirretrovírica muy activa (ARMA) durante el resto de la vida. Según los resultados de algunos estudios, la falta de adhesión a la terapia ARMA es el factor pronóstico más importante en relación con la falta de una reducción de la carga vírica a niveles inferiores al umbral de detección. Para lograr una supresión óptima parece ser necesario que el paciente tome $90-95 \%$ de las dosis indicadas, recomendación que se aplica por igual a todos los fármacos que forman parte de la terapia ARMA.

Las metas del tratamiento. Las metas principales del régimen con antirretrovíricos consisten en reducir a un mínimo la carga vírica durante el mayor tiempo posible; restaurar y conservar la función inmunitaria; mejorar la calidad de la vida; y reducir la morbilidad y mortalidad que suelen asociarse con la infección por VIH. Lamentablemente, no es posible erradicar el virus del organismo con los fármacos de los que se dispone en la actualidad, puesto que el reservorio de linfocitos infectados se establece en una fase muy temprana de la infección aguda. No obstante, el seguimiento de las recomendaciones terapéuticas emitidas por el USDHHS en su reciente informe ha dado por resultado una notable reducción de la mortalidad y morbilidad.

La reducción de la carga vírica en el plasma, que es factor de muy alto valor pronóstico, se traduce en beneficios clínicos apreciables. Se trata de una meta, sin embargo, que debe sopesarse a la luz de la necesidad de contar con varias opciones terapéuticas. Un cambio de un régimen terapéutico a otro puede agotar las posibilidades de tratamiento y debe efectuarse solamente si se cumplen distintas condiciones que se describirán más adelante.

La terapia ARMA a menudo aumenta el recuento de linfocitos $\mathrm{T} \mathrm{CD}^{+}$a $\geq 100-200$ células $/ \mathrm{mm}^{3}$, en general en consonancia con el grado de supresión de la carga vírica del plasma. Una buena respuesta linfocitaria al tratamiento puede observarse aun sin que la carga vírica se suprima en grado óptimo, y en estos casos se ignora cuánto pueda durar la restauración de la función inmunitaria. Por consiguiente, los profesionales de la salud deben tener en cuenta como factor pronóstico un aumento persistente del recuento linfocitario, además de la reducción de la carga vírica, aunque esta última se considera el factor pronóstico más importante. La tentación de cambiar el régimen terapéutico cuando hay cierto grado de viremia persistente debe resistirse si la respuesta linfocitaria es buena, pues no siempre se presenta resistencia medicamentosa en estos casos. Lo más importante es lograr una buena adhesión al tratamiento y hacer un seguimiento clínico minucioso.

Para lograr las metas terapéuticas aquí descritas, lo recomendado es administrar un régimen a base de tres fármacos antirretrovíricos. Con un régimen tal se logra suprimir la reproducción del VIH, restaurar ciertas respuestas inmunitarias específicas y conservar la función inmunitaria. Se consideran factores de buen pronóstico 1) una carga vírica basal pequeña, 2) recuentos basales de linfocitos $\mathrm{T} \mathrm{CD} 4^{+}$más altos, 3 ) una rápida reducción de la carga vírica después de iniciarse el tratamiento, y 4) la adhesión al régimen terapéutico. Aunque no todos los pacientes

CUADRO 1. Principales grupos terapéuticos de fármacos antirretrovíricos para el tratamiento de la infección por VIH-1

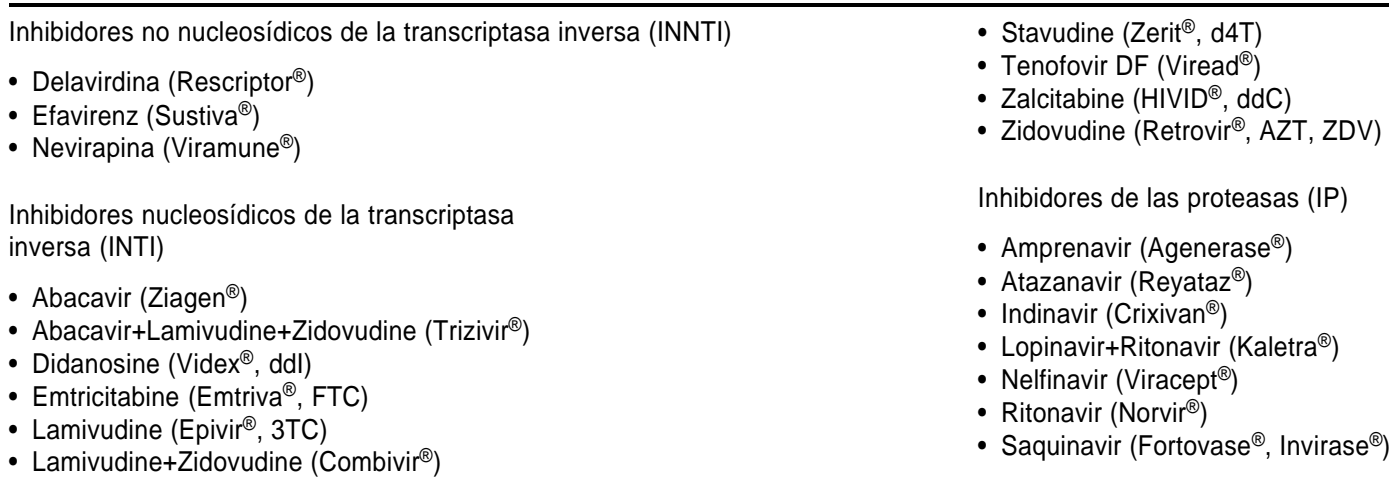


CUADRO 2. Regímenes antirretrovíricos recomendados para el tratamiento de la infección por VIH-1 en pacientes sin tratamiento anterior con antirretrovíricos

\begin{tabular}{|c|c|c|}
\hline Regímenes & & No. diario de píldoras \\
\hline \multicolumn{3}{|l|}{ Regímenes a base de INNTI } \\
\hline Regímenes preferidos & $\begin{array}{l}\text { Efavirenz + lamivudina + (zidovudina o tenofovir DF o estadovudina }{ }^{a} \text { ), salvo } \\
\text { en el caso de mujeres embarazadas o que pueden quedar embarazadas }\end{array}$ & 3-5 píldoras/día \\
\hline Regímenes alternativos & $\begin{array}{l}\text { Efavirenz + lamivudina + didanosina, salvo en el caso de mujeres } \\
\text { embarazadas o que pueden quedar embarazadas } \\
\text { Nevapirina + lamivudina + (zidovudina o estadovudina o didanosina) }\end{array}$ & $\begin{array}{l}\text { 3-5 píldoras/día } \\
\text { 4-6 píldoras/día }\end{array}$ \\
\hline \multicolumn{3}{|l|}{ Regímenes a base de IP } \\
\hline $\begin{array}{l}\text { Regímenes preferidos } \\
\text { Regímenes alternativos }\end{array}$ & $\begin{array}{l}\left.\left.\text { Kaletra }{ }^{\circledR} \text { (lopinavir + ritnoavir }\right)+ \text { lamivudina + (zidovudina o estadovudina }\right) \\
\left.\text { Amprenavir + ritonavir }{ }^{b}+\text { lamivudina + (zidovudina o estadovudina }\right)\end{array}$ & 8-10 píldoras/día \\
\hline & Indinavir + lamivudina + (zidovudina o estadovudina) & 12-14 píldoras/día \\
\hline & Indinavir + ritonavir ${ }^{b}+$ lamivudina + (zidovudina o estadovudina $)$ & 8-10 píldoras/día \\
\hline & Nelfinavirc + lamivudina + (zidovudina o estadovudina) & 8-12 píldoras/día \\
\hline & $\begin{array}{l}\text { Saquinavir }(\operatorname{cgb} \text { o cgd })^{\mathrm{d}}+\text { ritonavir }^{\mathrm{c}}+\text { lamivudina }+(\text { zidovudina } 0 \\
\text { estadovudina) }\end{array}$ & $\begin{array}{l}\text { 6-14 píldoras/día } \\
\text { 14-16 píldoras/día }\end{array}$ \\
\hline
\end{tabular}

Régimen triple a base de INTI como alternativa a los regímenes a base de IP o de INNTI

Regímenes alternativos

Abacavir + lamivudina + zidovudina

2 píldoras/día

Abacavir + lamivudina + estadovudina

4-6 píldoras/día

Nota: INNTI = inhibidores no nucleosídicos de la transcriptasa inversa; IP = inhibidores de las proteinasas; $I N T I$ = inhibidores nucleosídicos de la transcriptasa inversa a Según datos preliminares basados en 96 semanas, la combinación de estadovudina + lamivudina se acompaña de una mayor incidencia de lipodistrofias y dislipidemias que la de tenofovir + lamivudina.

b Ritnoavir a dosis bajas (100-400 mg).

c Pronto se dispondrá de nelfinavir en tabletas de $625 \mathrm{mg}$.

${ }^{\mathrm{d}} \mathrm{cgb}=$ cápsula gelatinosa blanda; cgd = cápsula gelatinosa dura

responden por igual, una manera de lograr buenos resultados consiste en secuenciar los medicamentos y en mantener abiertas para un futuro todas las posibilidades terapéuticas posibles.

\section{Grupos de fármacos antirretrovíricos y regímenes terapéuticos}

Los fármacos de los que se dispone para el tratamiento de pacientes infectados por el VIH se dividen en tres grupos terapéuticos generales, de los cuales derivan los tres regímenes básicos que se recomiendan en la actualidad (cuadros 1 y 2). Son los siguientes:

1. los regímenes a base de inhibidores no nucleosídicos de la transcriptasa inversa (INNTI, por nonnucleoside reverse transcriptase inhibitors), sin inhibidores de las proteinasas (IP, por protease inhibitors)

2. los regímenes a base de IP sin INNTI, y
3. los regímenes a base de inhibidores nucleosídicos de la transcriptasa inversa (INTI, por nucleoside reverse transcriptase inhibitors), sin IP $\mathrm{y} \sin$ INNTI.

El uso de regímenes de los que se omiten antirretrovíricos pertenecientes a ciertos otros grupos -se les suele llamar regímenes conservadores de grupos terapeúticos- radica en la necesidad de poder reservar para más tarde uno o más de los grupos terapéuticos omitidos, con lo cual también se evita o retrasa la aparición de reacciones adversas a un grupo en particular. Las ventajas y desventajas de los diferentes fármacos y regímenes se detallan en los cuadros 3 y 4 . Finalmente, en el cuadro 5 se presentan los regímenes o componentes que no deben administrarse nunca como parte del tratamiento de la infección por VIH debido a su dudosa efiacia contra el virus, su toxicidad y otras consideraciones farmacológicas. 
CUADRO 3. Ventajas y desventajas de los fármacos antirretrovíricos que forman parte de los regímenes recomendados para iniciar el tratamiento de pacientes infectados por VIH

\begin{tabular}{|c|c|c|c|}
\hline Grupo terapéutico & Agente(s) antirretrovírico(s) & Ventajas & Desventajas \\
\hline \multirow[t]{10}{*}{ INNTI } & & Ventajas del grupo de los INNTI & Desventajas del grupo de los INNTI \\
\hline & & \multirow{2}{*}{$\begin{array}{l}\text { Menor distribución inadecuada de la } \\
\text { grasa corporal y de lispidemias que } \\
\text { con los regímenes a base de IP }\end{array}$} & $\begin{array}{l}\text { La resistencia depende de una sola } \\
\text { mutación }\end{array}$ \\
\hline & & & Resistencia cruzada con otros \\
\hline & & \multirow{3}{*}{$\begin{array}{l}\text { Permite reservar los IP para uso } \\
\text { futuro }\end{array}$} & INNTI \\
\hline & & & Erupción cutánea \\
\hline & & & $\begin{array}{l}\text { Posible interacción con la } \\
\text { citocromooxidasa P450 }\end{array}$ \\
\hline & \multirow[t]{2}{*}{ Efavirenz } & Fuerte actividad antirretrovírica & Efectos neuropsiquiátricos adversos \\
\hline & & $\begin{array}{l}\text { Pocas píldoras y poca frecuencia } \\
\text { (1 tableta al día) }\end{array}$ & $\begin{array}{l}\text { Teratogénico en primates no } \\
\text { humanos, contraindicado durante el } \\
\text { embarazo y desaconsejable en } \\
\text { mujeres que pueden quedar } \\
\text { embarazadas }\end{array}$ \\
\hline & \multirow[t]{2}{*}{ Nevirapina } & \multirow[t]{2}{*}{$\begin{array}{l}\text { Más pruebas de inocuidad en } \\
\text { embarazadas }\end{array}$} & $\begin{array}{l}\text { Mayor incidencia de erupción } \\
\text { y de reacciones graves de } \\
\text { hipersensibilidad poco frecuentes, } \\
\text { que con otros INNTI }\end{array}$ \\
\hline & & & $\begin{array}{l}\text { Mayor incidencia de hepatotoxicidad } \\
\text { que con otros INNTI; algunos casos } \\
\text { de necrosis hepática grave }\end{array}$ \\
\hline \multirow[t]{14}{*}{ IP } & & Ventajas del grupo de los IP & Desventajasa del grupo de los IP \\
\hline & & $\begin{array}{l}\text { Se pueden reservar los NRRTI para } \\
\text { uso futuro }\end{array}$ & $\begin{array}{l}\text { Complicaciones metabólicas: } \\
\text { distribución anómala de la grasa } \\
\text { corporal, dislipidemias, resistencia a } \\
\text { la insulina }\end{array}$ \\
\hline & & & $\begin{array}{l}\text { Inhiben la enzima CYP3A4 y sus } \\
\text { sustratos. Puede haber interacción } \\
\text { medicamentosa (esp. con los } \\
\text { regímenes a base de ritonavir) }\end{array}$ \\
\hline & \multirow[t]{3}{*}{ Lopinavir/ritonavir } & Fuerte actividad antirretrovírica & Intolerancia digestiva \\
\hline & & \multirow{2}{*}{$\begin{array}{l}\text { Viene en fórmula adicional conocida } \\
\text { por Kaletra }{ }^{\circledR}\end{array}$} & Hiperlipidemia \\
\hline & & & $\begin{array}{l}\text { Poca experiencia acerca del uso en } \\
\text { embarazadas } \\
\text { Hay requisitos alimentarios }\end{array}$ \\
\hline & \multirow[t]{3}{*}{ Amprenavir/ritonavir } & No hay efectos alimentarios & Menos experiencia con su uso \\
\hline & & $\begin{array}{l}\text { Régimen de uns dosis diaria } \\
\text { aprobado por el FDA }\end{array}$ & $\begin{array}{l}\text { Erupciones cutáneas } \\
\text { Frecuentes }\end{array}$ \\
\hline & & & $\begin{array}{l}\text { Muchas píldoras y cápsulas } \\
\text { grandes }\end{array}$ \\
\hline & \multirow[t]{3}{*}{ Indinavir } & \multirow{3}{*}{$\begin{array}{l}\text { Se tiene experiencia respecto de su } \\
\text { eficacia virológica e inmunológica a } \\
\text { largo plazo }\end{array}$} & $\begin{array}{l}3 \text { dosis diarias y restricciones } \\
\text { alimentarias redujeron la adhesión }\end{array}$ \\
\hline & & & $\begin{array}{l}\text { Hay que tomar abundates líquidos } \\
(1,5-2 \text { litros de líquido al día) }\end{array}$ \\
\hline & & & Nefrolitiasis \\
\hline & \multirow[t]{2}{*}{ Indinavir/ritonavir } & \multirow{2}{*}{$\begin{array}{l}\text { Ritonavir a dosis bajas } \uparrow \mathrm{T}_{1 / 2} \text { y la } \\
\text { Cmin del indinavir y permite dos } \\
\text { dosis al día en vez de tres }\end{array}$} & $\begin{array}{l}\text { Posible mayor incidencia de } \\
\text { nefrolitiasis que con indinavir }\end{array}$ \\
\hline & & & $\begin{array}{l}\text { Hay que tomar abundantes líquidos } \\
\text { (1,5-2 litros al día) }\end{array}$ \\
\hline
\end{tabular}

(continúa) 
CUADRO 3. (Continuación)

\begin{tabular}{|c|c|c|c|}
\hline Grupo terapéutico & Agente(s) antirretrovírico(s) & Ventajas & Desventajas \\
\hline & \multirow[t]{2}{*}{ Nelfinavir } & \multirow{2}{*}{$\begin{array}{l}\text { Mayor experiencia en mujeres } \\
\text { embarazadas que con otros IP }\end{array}$} & Diarrea \\
\hline & & & $\begin{array}{l}\text { Mayor frecuencia de fracaso } \\
\text { virológico que con otros IP en } \\
\text { ensayos comparativos }\end{array}$ \\
\hline & Saquinavir (cgd o cgb) + ritonavir & $\begin{array}{l}\text { Ritonavir a dosis bajas reduce las } \\
\text { dosis diarias de saquinavir y su } \\
\text { frecuencia; } \uparrow \text { su Cmax, Cmin y } \mathrm{T}_{1 / 2}\end{array}$ & $\begin{array}{l}\text { Intolerancia digestiva (peor con las } \\
\mathrm{cgb} \text { que con las cgd) }\end{array}$ \\
\hline
\end{tabular}

INTI

Pilar establecido de la terapia antirretrovírica combinada

Casos raros pero peligrosos de acidosis láctica con esteatosis notificada en conexión con la mayoría de los INTI

Régimen triple a base de INTI

El tratamiento dual con INTI es el pilar de la terapia

Zidovudina + lamivudina

combinada a base de tres fármacos o más.
Abacavir + zidovudina + lamivudina se obtiene en fórmula adicional conocida por Combivir ${ }^{\circledR}$

Mínimo de interacciones medicamentosas

Permite reservar IP y INNTI para uso futuro

Experiencia virológica más completa y favorable

Viene en fórmula adicional llamada Combivir $^{\odot}$ - fácil dosificación

Ningún efecto alimentario

Lamivudina - efectos secundarios mínimos

Estavudina + lamivudina

Tenofovir + lamivudina

Didanosina + lamivudina
Ningún efecto alimentario

Una dosis diaria (cuando se disponga de una formulación de liberación lenta)

Buena respuesta virológica cuando se usa con efavirenz

Buena tolerancia

Una dosis diaria

Una dosis diaria
Respuesta virológica inferior a la obtenida con los regímenes a base de efavirenz

Respuesta virológica inferior que con indinavir en pacientes con valores basales de ARN de $\mathrm{VIH}$ $>100000$ copias $/ \mathrm{mL}$

Posibles reacciones de hipersensibilidad a abacavir

Posible mayor incidencia de toxicidad mitocondrial con estavudina que con otros INT

Supresión de la médula ósea con zidovudina

Intolerancia digestiva

Efectos adversos asociados con estavudina:

Neuropatía periférica, lipoatrofia, hipergalactosemia y acidosis láctica, casos de debilidad motora ascendente progresiva, posible hiperlipidemia

Faltan datos acerca del uso de tenofovir en pacientes con insuficiencia renal

Tenofovir - ha habido informes de afectación renal

Tenofovir - hay requisitos alimentarios

Neuropatía periférica, pancreatitis asociación con didanosina

Efecto alimentario - debe tomarse con estómago vacío

Nota: INNTI = inhibidores no nucleosídicos de la transcriptasa inversa; IP = inhibidores de las proteinasas; INTI = inhibidores nucleosídicos de la transcriptasa inversa. 
CUADRO 4. Ventajas y desventajas de los regímenes de conservación de grupos terapéuticos recomendados para el tratamiento de pacientes infectados por VIH

\begin{tabular}{|c|c|c|c|c|}
\hline Régimen & Posibles ventajas & $\begin{array}{l}\text { Posibles } \\
\text { desventajas }\end{array}$ & $\begin{array}{l}\text { por interacción } \\
\text { medicamentos }\end{array}$ & $\begin{array}{l}\text { Complicaciones y } \\
\text { efecto sobre } \\
\text { futuras opciones }\end{array}$ \\
\hline \multirow{4}{*}{$\begin{array}{l}\text { Régimen ARMA a } \\
\text { base de IP } \\
\text { (conservador de } \\
\text { INNTI) }\end{array}$} & $\begin{array}{l}\text { Eficacia clínica, } \\
\text { virológica e inmunológica } \\
\text { bien documentada }\end{array}$ & $\begin{array}{l}\text { Algunos regímenes son } \\
\text { difíciles de usar y de } \\
\text { observar }\end{array}$ & \multirow{4}{*}{$\begin{array}{l}\text { Inhibición leve a intensa } \\
\text { de la vía de la } \\
\text { citocromooxidasa P450; } \\
\text { el ritonavir es quizá el } \\
\text { inhibidor más fuerte } \\
\text { (aunque este efecto se } \\
\text { puede aprovechar para } \\
\text { realzar las concentra- } \\
\text { ciones de otros IP) }\end{array}$} & $\begin{array}{l}\text { Permite reservar los } \\
\text { INNTI para casos de } \\
\text { fracaso terapéutico }\end{array}$ \\
\hline & $\begin{array}{l}\text { Varias mutaciones } \\
\text { necesarias para que } \\
\text { haya resistencia }\end{array}$ & \multirow{3}{*}{$\begin{array}{l}\text { A menudo son efectos } \\
\text { secundarios a largo } \\
\text { plazo la lipodistrofia } \\
\text { la hiperlipidemia y la } \\
\text { resistencia a la insulina }\end{array}$} & & \multirow[t]{3}{*}{$\begin{array}{l}\text { La resistencia propicia la } \\
\text { resistencia cruzada con } \\
\text { otros IP }\end{array}$} \\
\hline & $\begin{array}{l}\text { Se evitan los efectos } \\
\text { adversos de los INNTI }\end{array}$ & & & \\
\hline & $\begin{array}{l}\text { Ataca al VIH en dos } \\
\text { puntos del ciclo de repro- } \\
\text { ducción (transcriptasa } \\
\text { inversa y IP) }\end{array}$ & & & \\
\hline \multirow[t]{3}{*}{$\begin{array}{l}\text { Régimen ARMA a } \\
\text { base de INNTI } \\
\text { (conservador de IP) }\end{array}$} & $\begin{array}{l}\text { Eficacia virológica e } \\
\text { inmunológica bien } \\
\text { documentada }\end{array}$ & \multirow[t]{3}{*}{$\begin{array}{l}\text { La resistencia está dada } \\
\text { por un número limitado } \\
\text { de mutaciones }\end{array}$} & \multirow[t]{3}{*}{$\begin{array}{l}\text { Menos interacciones } \\
\text { medicamentosas que } \\
\text { con los IP }\end{array}$} & $\begin{array}{l}\text { Permite reservar los IP } \\
\text { para casos de fracaso } \\
\text { terapéutico }\end{array}$ \\
\hline & $\begin{array}{l}\text { Se evitan los efectos } \\
\text { secundarios de los IP }\end{array}$ & & & \multirow{2}{*}{$\begin{array}{l}\text { La resistencia } \\
\text { normalmente propicia la } \\
\text { resistencia cruzada a } \\
\text { toda la familia de INNTI }\end{array}$} \\
\hline & $\begin{array}{l}\text { Facilidad de uso y } \\
\text { observancia mejores que } \\
\text { con los IP }\end{array}$ & & & \\
\hline \multirow[t]{3}{*}{$\begin{array}{l}\text { Régimen triple a } \\
\text { base de INTI } \\
\text { (conservador de } \\
\text { INNTI y IP) }\end{array}$} & $\begin{array}{l}\text { En general, mayor facili- } \\
\text { dad de uso y observan- } \\
\text { cia que con los IP }\end{array}$ & \multirow[t]{3}{*}{$\begin{array}{l}\text { Menos eficacia virológica } \\
\text { que la observada con el } \\
\text { régimen a base de EFV }\end{array}$} & \multirow[t]{3}{*}{$\begin{array}{l}\text { No hay interacción con la } \\
\text { citocromooxidasa P450 }\end{array}$} & \multirow[t]{3}{*}{$\begin{array}{l}\text { Permite reservar tanto } \\
\text { los IP como los INNTI } \\
\text { para casos de fracaso } \\
\text { terapéutico }\end{array}$} \\
\hline & $\begin{array}{l}\text { Se evitan los efectos } \\
\text { secundarios de los IP } \\
\text { y INNTI }\end{array}$ & & & \\
\hline & $\begin{array}{l}\text { Es raro que haya } \\
\text { resistencia cruzada a } \\
\text { todos los INTI cuando } \\
\text { fracasa el régimen inicial }\end{array}$ & & & \\
\hline
\end{tabular}

Nota: INNTI = inhibidores no nucleosídicos de la transcriptasa inversa; IP = inhibidores de las proteinasas; INTI = inhibidores nucleosídicos de la transcriptasa inversa.

\section{RESUMEN}

Las recomendaciones más recientes del Departamento de Salud y Servicios Sociales de los Estados Unidos de América, que fueron emitidas en julio de 2003, tienen por finalidad facilitar la elección de un régimen de tratamiento para personas infectadas por el VIH, habida cuenta de la gran variedad de fármacos antirretrovírticos que han surgido en años recientes. Los fármacos que han mostrado mayor eficacia y que constituyen la base del tratamiento actual pertenecen a tres grandes grupos terapéuticos: los inhibidores nucleosídicos de la transcriptasa inversa, los inhibidores no nucleosídicos de la transcriptasa inversa y los inhibidores de las proteinasas. Son estos grupos, a su vez, los que integran los llamados regímenes conservadores de grupos terapéuticos, cuya finalidad es dejar de reserva para el futuro algunos grupos de fármacos por si se presenta resistencia a los utilizados inicialmente.

El tratamiento de la infección por VIH con antirretrovíricos es complejo y difícil de cumplir, dado el elevado número de pastillas y de dosis diarias, y antes de iniciarse en pacientes asintomáticos es de rigor sopesar sus ventajas y beneficios. En la decisión es indispensable tener en cuenta el deseo del paciente de ser tratado y su estado clínico general, en particular su carga vírica en plasma y su recuento plasmático de linfocitos $\mathrm{T} \mathrm{CD} 4^{+}$, cuya determinación se debe hacer solamente con métodos que hayan sido aprobados y con un mismo método a lo largo de todo el seguimiento para garantizar la uniformidad de los resultados.

El tratamiento debe tener por meta reducir, durante el mayor tiempo posible, la carga vírica plasmática por debajo del umbral de detección recomendado; restaurar y conservar la función inmunitaria; mejorar la calidad de la vida y reducir la mortalidad y morbilidad que suelen acompañar a la infección por VIH. Aquellos pacientes en quienes fracasa el régimen inicial deben ser sometidos a un cambio de régimen que deberá basarse en un cuidadoso estudio de sus antecedentes terapéuticos y en pruebas de resistencia medicamentosa. En toda decisión también cabe tener en cuenta las posibilidades de adhesión al tratamiento y la toxicidad de los diversos fármacos alternativos. Dada la rapidez con que se producen cambios en la disponibilidad de fármacos para el tratamiento de la infección por VIH, se recomienda a los profesionales de la salud a cargo del tratamiento de pacientes infectados que procuren mantenerse al corriente de futuras modificaciones a las recomendaciones vigentes. 
CUADRO 5. Regímenes o componentes antirretrovíricos que no deben recetarse nunca para el tratamiento de pacientes infectados por VIH

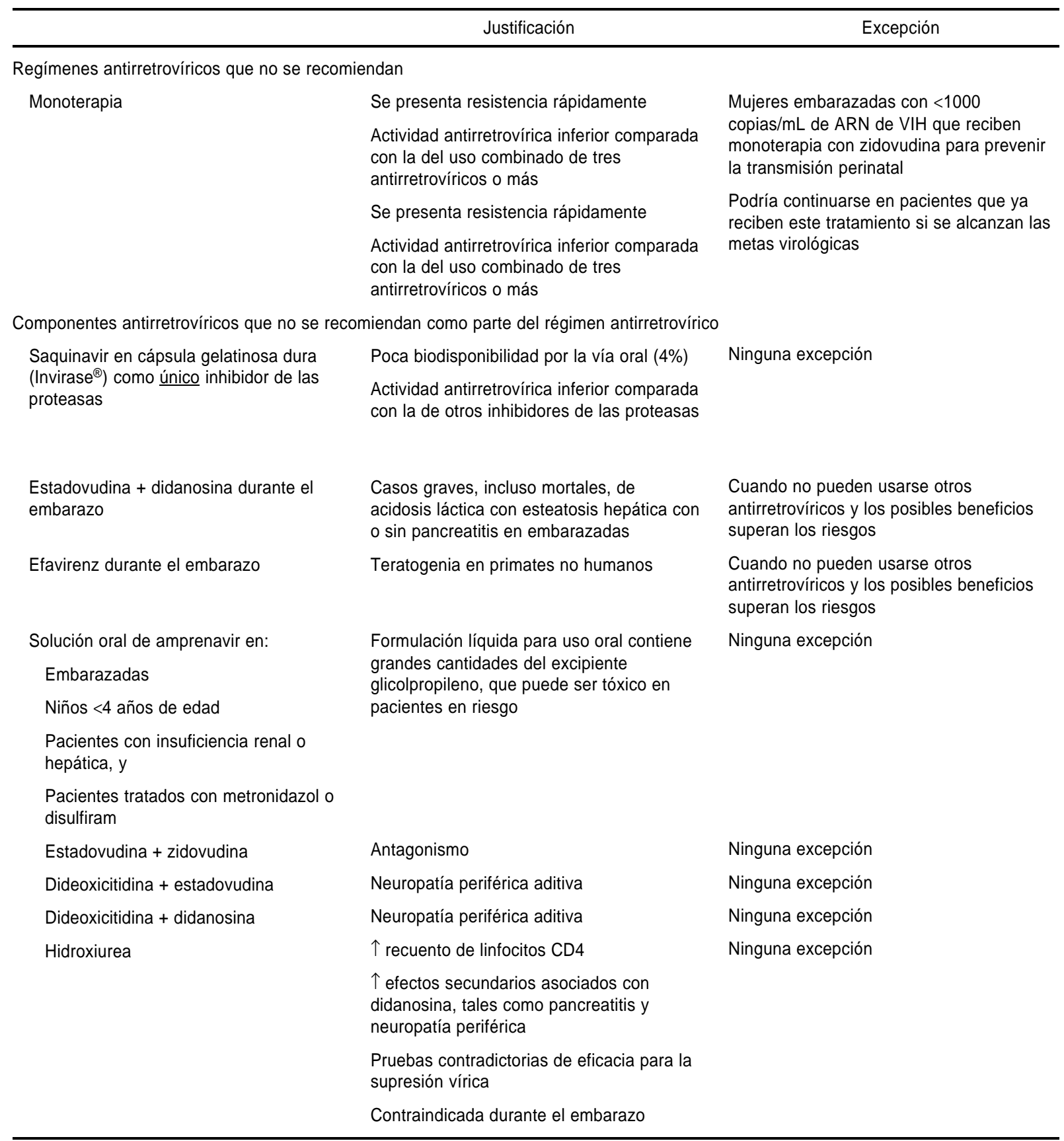

\section{REFERENCIAS}

1. Centers for Disease Control and Prevention. Report of the NIH Panel to Define Principles of Therapy of HIV Infection and Guidelines for the use of antiretroviral agents in HIV-infected adults and adolescents. MMWR 1998;47[RR-5]:1-41. 